\title{
Effect of Electron Beam Welding Parameters on Temperature and Stress Field of AISI P20 Tool Steel in Vacuum Roll-cladding Process
}

lanyu mao ( $\sim$ lanyumaocn@outlook.com )

Northeastern University State Key Laboratory of Rolling and Automation https://orcid.org/0000-00024191-2036

Zongan Luo

Northeastern University

Yingying Feng

Northeastern University

Xiaoming Zhang

Northeastern University

\section{Research Article}

Keywords: Ultra-heavy AISI P20 plates, Electron beam welding package, Vacuum roll-cladding process, Temperature field, Stress field

Posted Date: June 16th, 2021

DOI: https://doi.org/10.21203/rs.3.rs-608827/v1

License: (c) (1) This work is licensed under a Creative Commons Attribution 4.0 International License. Read Full License

Version of Record: A version of this preprint was published at The International Journal of Advanced Manufacturing Technology on September 7th, 2021. See the published version at https://doi.org/10.1007/s00170-021-07959-7. 


\section{Effect of electron beam welding parameters on temperature and stress field of AISI P20 tool steel in vacuum roll-cladding process}

\section{Lanyu Mao, Zongan Luo*, Yingying Feng, Xiaoming Zhang}

Author affiliations:

1. Lanyu Mao, State Key Laboratory of Rolling and Automation, Northeastern University, Shenyang, 110819, P R China.

Email address: lanyumaocn@outlook.com

2. Zongan Luo*, the corresponding author, State Key Laboratory of Rolling and Automation, Northeastern University, Shenyang, 110819, P R China.

Email address: 1uoza@ral.neu.edu.cn, Tel: 86-024-83689715, Fax: 86-024-23906472

3. Yingying Feng, State Key Laboratory of Rolling and Automation, Northeastern University, Shenyang, 110819, P R China.

Email address: fengyy@ral.neu.edu.cn

4. Xiaoming Zhang, State Key Laboratory of Rolling and Automation, Northeastern University, Shenyang, 110819, P R China.

Email address: zhangxm@ral.neu.edu.cn 


\title{
Effect of electron beam welding parameters on temperature and stress field of AISI P20 tool steel in vacuum roll-cladding process
}

\begin{abstract}
ABSTACT
Vacuum roll-cladding (VRC) is an effective method to produce high quality ultra-heavy AISI P20 plate steel. In the process of VRC, reasonable welding process of electron beam welding (EBW) can significantly avoid welding cracks and reduce the cost. In this paper, the electron beam welding process of AISI P20 tool steel was simulated by using a combined heat source model based on finite element method, and the temperature field and stress field under different welding parameters were studied respectively. The results showed that welding parameters have a greater effect on weld penetration than that of weld width, which making the aspect ratio increases with the increase of welding current, and decrease with the increase of welding speed. The weld morphologies were consistent with those of the modeling and the measured thermal heat curves were good agreement with those of simulated, which was verified the feasibility and effectiveness of temperature fields. The results of stress fields under different welding parameters indicated that lower welding speed and higher welding current resulting in lower residual stress at welded joint, which means lower risk of cracking after EBW. The results of this study have been successfully applied to industrial production.
\end{abstract}

Keywords: Ultra-heavy AISI P20 plates; Electron beam welding package; Vacuum roll-cladding process; Temperature field; Stress field

\section{Highlights :}

- The keyhole effect constrains the residual stress at the weld

- The weld penetration is more sensitive to welding parameters

- A larger aspect ratio results in low risk of welding crack

- The optimized welding parameter has been successfully applied to production line 


\section{Introduction}

Plastics, together with steel, wood and cement, constitute the four basic materials of modern society in the 21 st century. With the increasing demand of large-scale and precision plastic products, it is necessary to develop ultra-heavy and high precision steel plates. AISI P20 tool steel is commonly employed in the manufacture of molds for plastics because of its high wear and corrosion resistances and excellent machining properties [1,2]. Traditional production methods of ultra-heavy AISI P20 plates process, such as continuous casting and rolling, have many shortcomings. The microstructure and properties of the rolled ultra-heavy plates are inhomogeneous due to the center segregation, small rolling deformation and low rate of heat transfer. These defects seriously affected the overall properties of the steel plates and generated internal cracks [3-7]. In recent years, with the appearance of laminated metal composites (LMC), two or more layers of pure, homogeneous and dense thin continuous casting billets can be rolled into a high quality extra-thick plate, which not only solved the above performance defects, but also reduced the production cost. Vacuum Roll-Cladding (VRC) technology is widely used in the fabrication of high quality ultra-heavy LMC. The VRC process is shown in Fig. 1, the purity of the interface is crucial to the healing of interface during hot rolling process. Thus, the layers are usually packaged by electron beam welding (EBW) under high vacuum conditions. However, The welding performance of P20 steel is poor because of its relatively high carbon content [8]. Therefore, it is necessary to guarantee the weld quality and avoid cracks after EBW process. Compared to other welding methods, such as inert gas welding (TIG) and laser beam welding (LBW), EBW has higher energy density and larger depth-width ratio, resulting in a narrower HAZ and lower residual stress at welded joint [9-14].

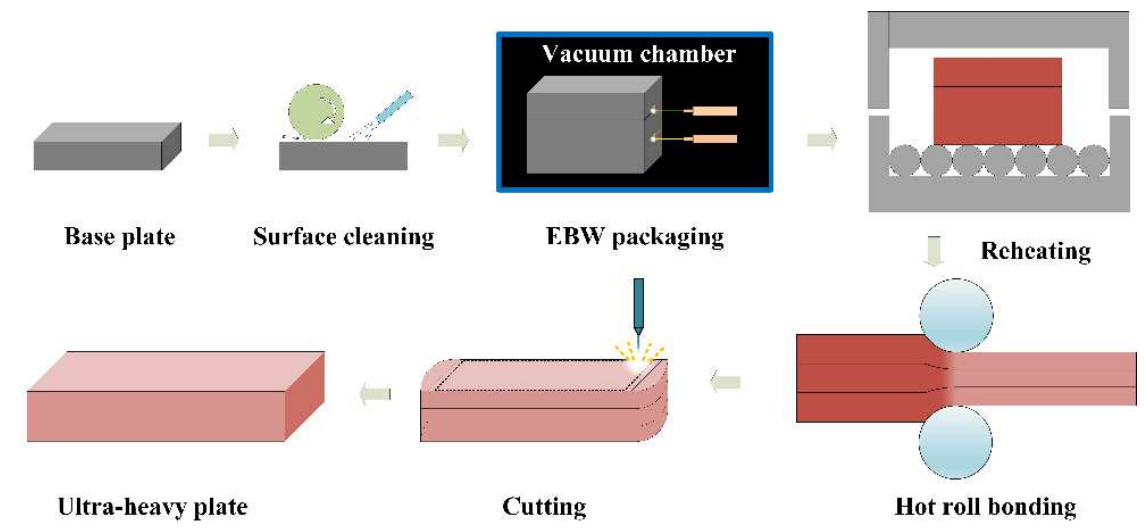

Fig. 1 The VRC process

Meanwhile, the weld residual stress is considered to be the main factor that affected the weld strength and welding cracks. Nevertheless, it should be realized that the welding residual stress is hard to measure by existing methods such as hole-drilling method and X-ray diffraction method [15]. These experiment tests have many limitations and large error due to the complexity of welding process and expensive costs. In order to obtain accurate residual stress value, researchers solved 
this problem based on finite element method (FEM) during the past decades. For the past few years, more and more accurate and persuasive results were obtained with the constant optimization of the mathematical model. Moreover, it should be clear that temperature distribution has a great effect on residual stress because deformation and residual stress are generated by temperature field. The characteristics of temperature field in EBW are mainly reflected in the following aspects [16,17]: (1) High concentration of heat in EBW process causes a large temperature gradient; (2) The temperature field changed continuously with the movement of heat source; (3) The heat transfer properties inside the metal transformed because of the formation of "keyhole". Hence, the effectiveness of stress field depends on the accuracy of the temperature field. The distributions of temperature field during EBW were widely reported in recent years. For instance, Huang et al [18] proposed a three-dimensional coupling model to predict keyhole and dynamics of weld pool in EBW, which successfully obtained the temperature field around keyhole, and the results are agree with the experimental data. HX Wang et al [19] analyzed plasma temperature during laser beam welding (LBW), which similar to EBW, and the results showed that maximum temperature can reach 13000 degrees. Fu et al [20] studied EBW with multi-beam on high temperature titanium alloy, the temperatures gradually lowered with the increase of the distance from weld because of the great heat gradient of EBW. They also found that the temperature uniformity of EBW can be improved by pre-heating and post heating.

Based on temperature field results, Hong et al [21] calculate residual stress and deformation of GH80A plates during EBW. With increase of distance from welding lines, the transverse stress develops to increase and always characterized as tensile stress. P Lacki et al [22] calculated effective stress distribution of 30HGSA steel tube during pulsed electron beam welding, the results indicated that maximal values of stress occur in bottom area of weld. Yan-jun LI et al [23] has conducted welding of Ti2AlNb alloys using electron beam. In their studies, plate produced more than 1000MPa tensile residual stress of longitudinal direction in the fusion zone. They also found wider weld has relatively low tensile stress in Z-direction, resulting in low risk for cracking. Since the temperature distribution in EBW is determined by the welding parameters, the welding parameters, especially the welding beam current and welding speed, have crucial impact on the residual stress. Therefore, it is of great significance to study the influence of different welding parameters on residual stress of EBW. Previous studies have mainly focused on various temperature fields and stress field under a specific welding parameter [24-28], and there were mainly reported the microstructure and properties of AISI P20 tool steel welded joint under TIG or LBW $[29,30]$. Little work has been done concerning on the influence of different welding parameters on residual stress fields of AISI P20 tool steel.

In this paper, a combined heat source model was used to simulated the EBW process of P20 steel. the temperature field and stress field were obtained under different EBW parameters. The thermal cycle curves at different positions were measured and weld morphologies were compared, both of them verified the accuracy of simulated results. Ultimately, the change rule of welding residual stresses under 
different welding parameters was analyzed.

\section{Experiments and methods}

\subsection{Material and procedures}

The material used in this study is commercial AISI P20 tool steel, produced by Jinan Steel Group, China. The chemical composition is $0.36 \mathrm{C}, 0.41 \mathrm{Si}, 1.3 \mathrm{Mn}, 1.86 \mathrm{Cr}$, $0.6 \mathrm{Ni}, 0.44 \mathrm{Mo}, 0.006 \mathrm{P}, 0.006 \mathrm{~S}$, the rest being $\mathrm{Fe}$, all in mass fraction. $\mathrm{P} 20$ steel plates with dimensions of $160 \times 200 \times 20 \mathrm{~mm}$ were welded using a THDW- $15 \mathrm{EBW}$ machine made by Guilin Shida technology co., LTD. The dimensions of the vacuum chamber are $1700 \mathrm{~mm}$ length, $650 \mathrm{~mm}$ width and $750 \mathrm{~mm}$ height, and the vacuum of the chamber is less than $10^{-2} \mathrm{~Pa}$ during welding process. The accelerating voltage is $80 \mathrm{kV}$ and the electron beam focused on the top surface of the specimens. The plates were grinded using 80-800-grit $\mathrm{SiC}$ paper and then cleaned by acetone and alcohol within 30 minutes before welding. The work-pieces with same thicknesses were welded to study the effect of welding parameters. The welding conditions are shown in Table 1

Table 1 Welding conditions of EBW packaging

\begin{tabular}{cccc}
\hline Case & Electron Current $(\mathrm{mA})$ & Welding Speed $(\mathrm{mm} / \mathrm{min})$ & Welding Power $(\mathrm{W})$ \\
\hline 1 & 40 & 300 & 3200 \\
2 & 40 & 400 & 3200 \\
3 & 40 & 600 & 3200 \\
4 & 50 & 300 & 4000 \\
5 & 50 & 400 & 4000 \\
6 & 50 & 600 & 4000 \\
7 & 60 & 300 & 4800 \\
8 & 60 & 400 & 4800 \\
9 & 60 & 600 & 4800 \\
\hline
\end{tabular}

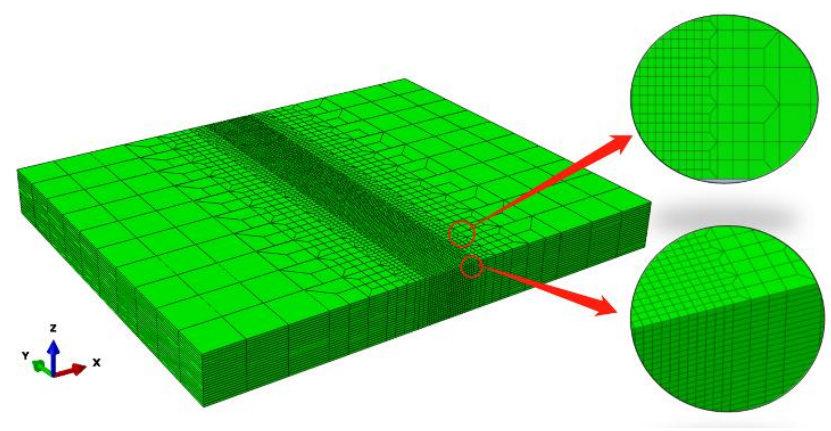

Fig. 2 Finite element model

According to the shape of plates, the models of plates were established and meshed. In order to improve calculation efficiency, symmetric model and transition 
grid were used in meshing (as shown in Fig.2). DC3D8 brick elements were employed in temperature field calculation. Reduced integral elements C3D8R were used in stress field calculation by sequential coupling method. The whole model was composed of 194,240 elements, with a total of 209,412 calculation nodes. The minimum size of element was $1 \mathrm{~mm}$ at the weld, and the maximum size of element was $10 \mathrm{~mm}$ at base metal. The thermophysical property parameters of AISI P20 were obtained by JMatPro material properties simulation software. The high temperature mechanical parameters of AISI P20 were obtained by thermal simulation test on MMS-200 thermomechanical simulator. The material properties under different temperature were shown in Fig 3.
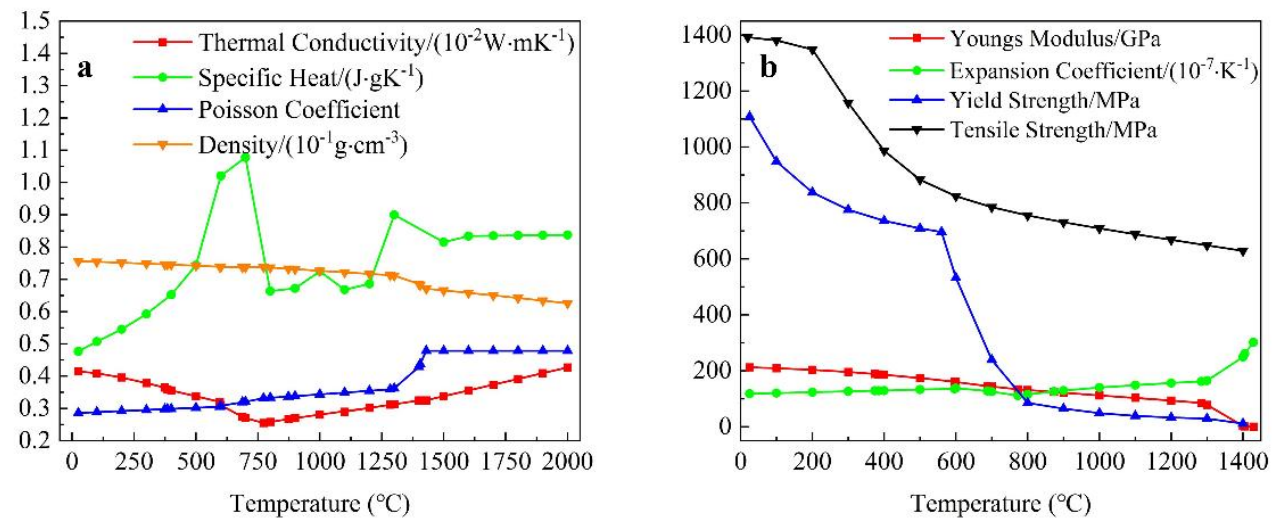

Fig. 3 Properties of AISI P20 at different temperature

(a) Thermal physical parameters; (b) Mechanical properties

\subsection{Mathematical model}

According to previous research results [18], the fusion line morphology of actual weld shows that electron beam distribution area is not the fusion area of large aspect ratio perpendicular to the workpiece surface, but more like the weld morphology formed by the superposition of two " $\mathrm{V}$ " types. Besides, the opening of the upper "V" type is larger than that of the lower "V" type. Thus, based on previous EBW studies [31-33] and morphologies of weld profile, a Gaussian surface heat source model was used to describe the heat flux distribution in each thickness layer, and an attenuation equation in the thickness direction was employed to simulate the characteristics of deep penetration. The schematic of heat source model combined by Gaussian surface heat source and attenuation body heat source was shown in Fig. 4. 


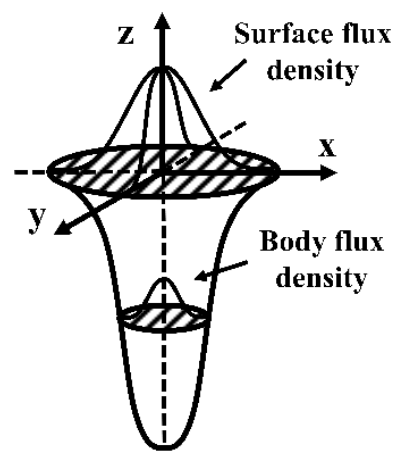

Fig. 4 Combined heat source model

The Mathematical model equation of combined heat source model can be expressed as Eq. (1). Where $Q_{s}$ and $Q_{v}$ are the energy of surface heat source and the energy of body heat source respectively, $R_{h}$ represents heating spot radius of the cross section at height $h, C_{S}$ is shape concentration factor of body heat source, $H$ is the depth of weld.

$$
q(x, y, z)=\left\{\begin{array}{l}
\frac{3 Q_{s}}{\pi R_{h}{ }^{2}} \exp \left(-\frac{3 x^{2}+3 y^{2}}{R_{h}{ }^{2}}\right) ; z=0 \text { or } z=H \\
\frac{3 c_{s} Q_{v}}{\pi H\left(1-1 / e^{3}\right)} \exp \left(\frac{-3 c_{s}}{\log (H / z)} \cdot\left(x^{2}+y^{2}\right)\right) ; z \in(0, H)
\end{array}\right.
$$

The heat conduction during EBW can be defined by Fourier equation and Energy conservation equation (expressed as Eq. (2) and Eq. (3) respectively). Where $\Phi x, \Phi y, \Phi z, \frac{\partial t}{\partial x}, \frac{\partial t}{\partial y}, \frac{\partial t}{\partial z}$ are heat flux and temperature gradient of $x, y, z$ directions, $\lambda$ is heat conductivity coefficient, $\Delta Q_{d}$ is net heat flow of the element, $\Delta Q_{v}$ is formation heat in element, $\Delta E$ is increment in internal energy.

$$
\left\{\begin{array}{l}
\Phi_{x}=-\lambda \frac{\partial t}{\partial x} d y d z \\
\Phi_{y}=-\lambda \frac{\partial t}{\partial y} d x d z \\
\Phi_{z}=-\lambda \frac{\partial t}{\partial z} d x d y \\
\Delta E=\Delta Q_{d}+\Delta Q_{v}
\end{array}\right.
$$

Heat conduction equation of system can be deduced by Eq. (2) and Eq. (3). Thus, the three-dimensional heat conduction differential equation can be expressed as Eq. (4). Where $\rho$ and $c$ are density and specific heat of workpiece, $\Phi$ is formation heat of internal heat source per unit volume per unit time, $\tau$ is unit interval, $a=\lambda / \rho c$ is thermal diffusivity. Due to the EBW conducted in vacuum chamber, the 
surface film condition can be ignored. Heat emissivity is set to 0.75. Initial temperature is set to $293 \mathrm{~K}$.

$$
\begin{aligned}
& \rho c \frac{\partial t}{\partial \tau}=\lambda\left(\frac{\partial^{2} t}{\partial x^{2}}+\frac{\partial^{2} t}{\partial y^{2}}+\frac{\partial^{2} t}{\partial z^{2}}\right)+\Phi \\
& \text { or } \frac{\partial t}{\partial \tau}=a\left(\frac{\partial^{2} t}{\partial x^{2}}+\frac{\partial^{2} t}{\partial y^{2}}+\frac{\partial^{2} t}{\partial z^{2}}\right)+\Phi / \rho c=a \nabla^{2} t+\Phi / \rho c
\end{aligned}
$$

\subsection{Temperature measurement}

Temperature measurement experiment was implemented to verify the veracity of temperature field. The K-type thermocouples produced by OMEGA were selected for tests. The diameter of the thermocouple line is $0.5 \mathrm{~mm}$. The upper limit of instantaneous temperature measurement of this thermocouple can reach $4250 \mathrm{~K}$. Five locations with a depth of $6 \mathrm{~mm}, 8 \mathrm{~mm}, 10 \mathrm{~mm}, 12 \mathrm{~mm}, 14 \mathrm{~mm}$ from the upper surface were selected for temperature measurement. LR8431-30 data acquisition instrument produced by HIOKI was used as temperature measuring instrument. Data was collected every $500 \mathrm{~ms}$ during the welding process.

\section{Results}

\subsection{Effects of welding parameters on temperature field}

Fig.5 shows the temperature distribution of different welding current under welding speed of $300 \mathrm{~mm} / \mathrm{min}$ at the same time. With the increase of welding current, the width of weld and heat affected zone extended. The maximum temperature on workpiece surface increased from $3152 \mathrm{~K}$ (Fig. 5a) to $3799 \mathrm{~K}$ (Fig. 5c) as the welding current increased from $40 \mathrm{~mA}$ to $60 \mathrm{~mA}$. Meanwhile, the length of welding pool gradually heightened due to the temperature increasement of workpiece. Fig. 6 shows the weld profiles of different welding current under welding speed of $300 \mathrm{~mm} / \mathrm{min}$. As shown in Fig. 6, the welds presented typically nail-shape, which was agreed with the results of previous studies [23,34]. The weld morphologies became longer and narrower with the increase of welding current.

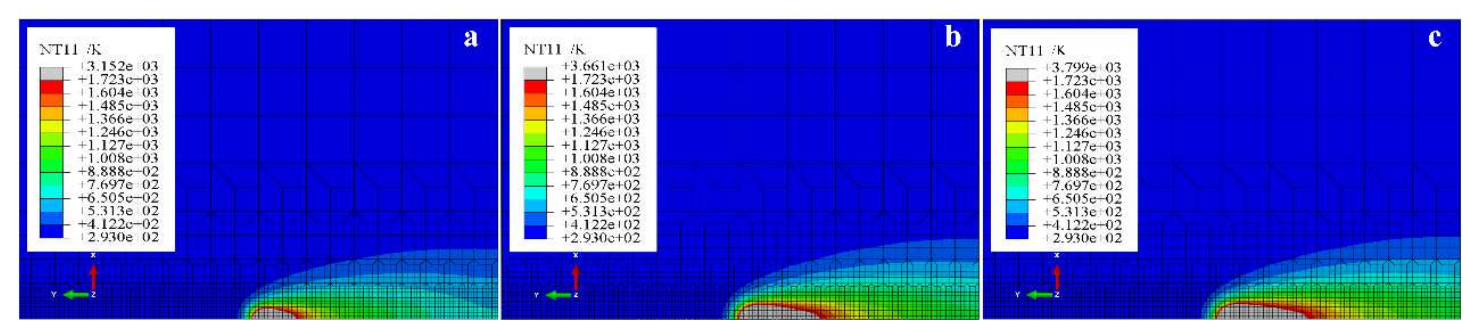

Fig. 5 Temperature field under different welding current at welding speed of $300 \mathrm{~mm} / \mathrm{min}$

(a) $40 \mathrm{~mA}$; (b) $50 \mathrm{~mA}$; (c) $60 \mathrm{~mA}$ 


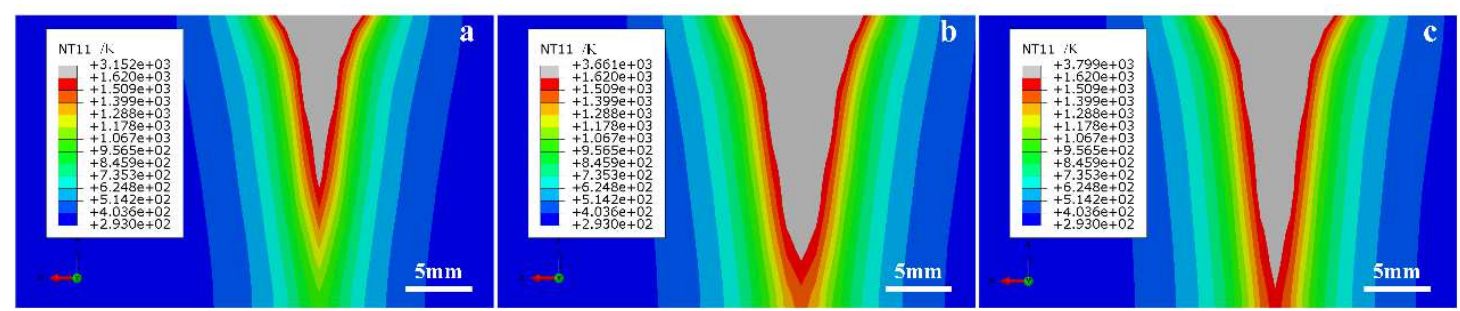

Fig. 6 Weld profiles under different welding current at welding speed of $300 \mathrm{~mm} / \mathrm{min}$

(a) $40 \mathrm{~mA}$; (b) $50 \mathrm{~mA}$; (c) $60 \mathrm{~mA}$

Fig. 7 presents the relationship between weld width/penetration and welding current under 3 kinds of welding speed conditions. Positive correlations were showed between weld width/penetration and welding current in 3 kinds of different welding speeds. However, there was a greater promotion of weld penetration than weld width. For welding speed of $300 \mathrm{~mm} / \mathrm{min}$, as the welding current increased, the weld width heightened from $5.2 \mathrm{~mm}$ to $6 \mathrm{~mm}$, while weld penetration gradually heightened from $10.6 \mathrm{~mm}$ to $18.5 \mathrm{~mm}$. Since the increase of weld penetration is more significant, the aspect ratio of weld heightened from 2.04 to 3.08 with the increase of welding current (shown as Fig. 7a). It's worth noting that the weld aspect ratio basically unchanged as welding current increased under welding speed of $600 \mathrm{~mm} / \mathrm{min}$, indicated that almost same growth rate of weld width and weld penetration under this welding speed (shown as Fig. 7c).
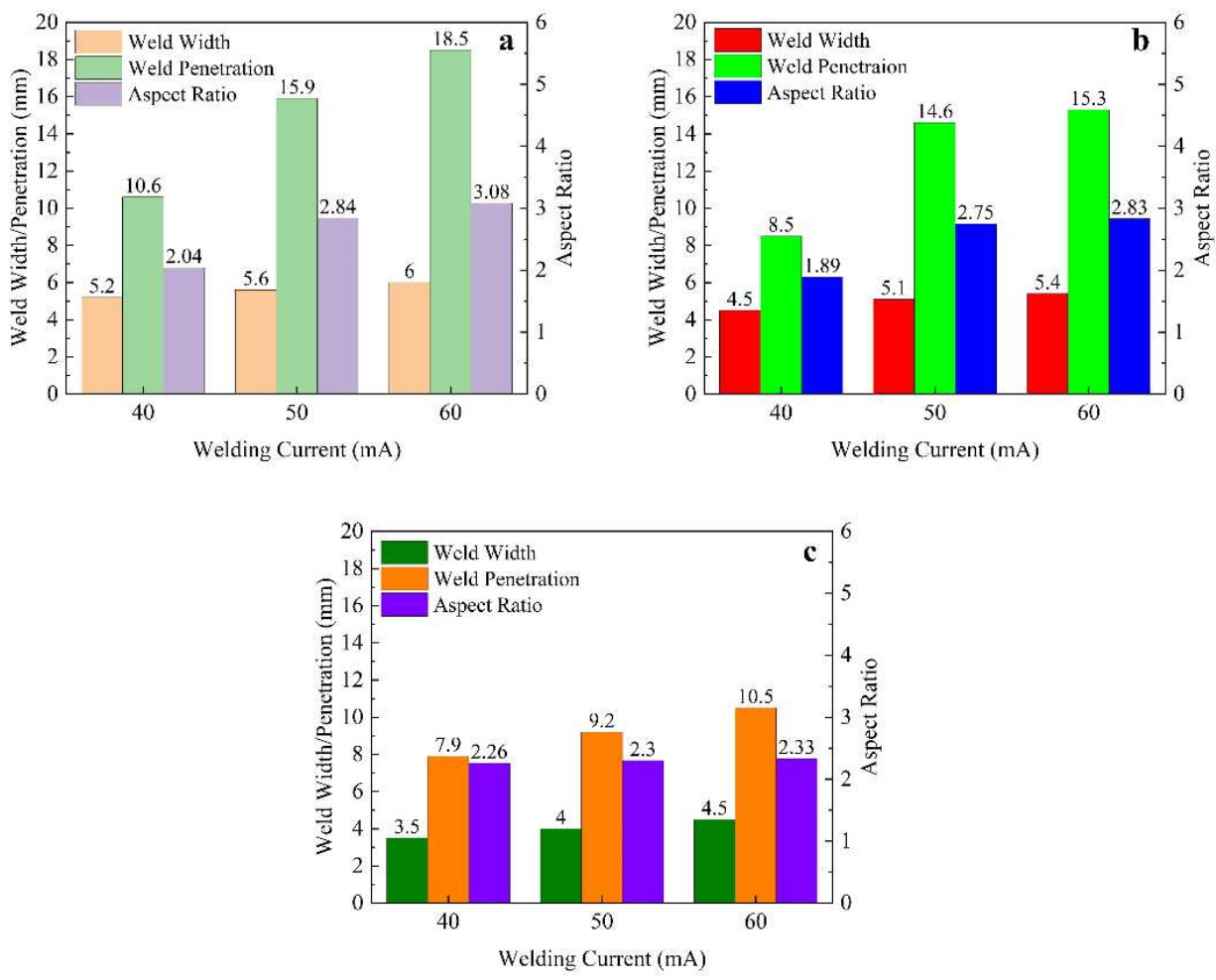

Fig. 7 Weld width/penetration under different welding current

Welding speed for (a) $300 \mathrm{~mm} / \mathrm{min}$; (b) $400 \mathrm{~mm} / \mathrm{min}$; (c) $600 \mathrm{~mm} / \mathrm{min}$

Fig. 8 shows the temperature field under different welding speed with welding current of $40 \mathrm{~mA}$ at the same position. As morphologies of weld pool shown in Fig. 8 , 
the weld width decreased with the increase of welding speed. The upper limit of temperature on workpiece surface lowered from $3661 \mathrm{~K}$ (Fig. 8a) to $2708 \mathrm{~K}$ (Fig. 8c). As the welding speed increased, time of heat source acting on the workpiece was shortened, which lead to the shrinkage of temperature field and the rapid decrease of weld pool length. Fig. 9 shows weld profiles under different welding speed at welding current of 50mA. The weld profiles presented nail-shape and funnel-shape in different welding speed as shown in Fig. 9a and Fig. 9c respectively. The weld morphology became shorter and wider with the increase of welding speed. Meanwhile, the weld profile changed from nail-shape to funnel-shape as the welding speed increased.

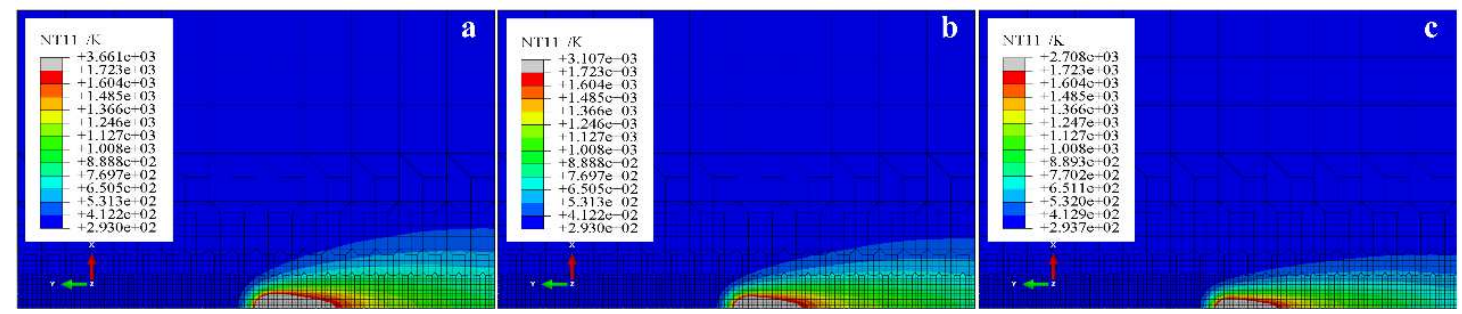

Fig. 8 Temperature field under different welding speed at welding current of $50 \mathrm{~mA}$ (a) $300 \mathrm{~mm} / \mathrm{min}$; (b) $400 \mathrm{~mm} / \mathrm{min}$; (c) $600 \mathrm{~mm} / \mathrm{min}$

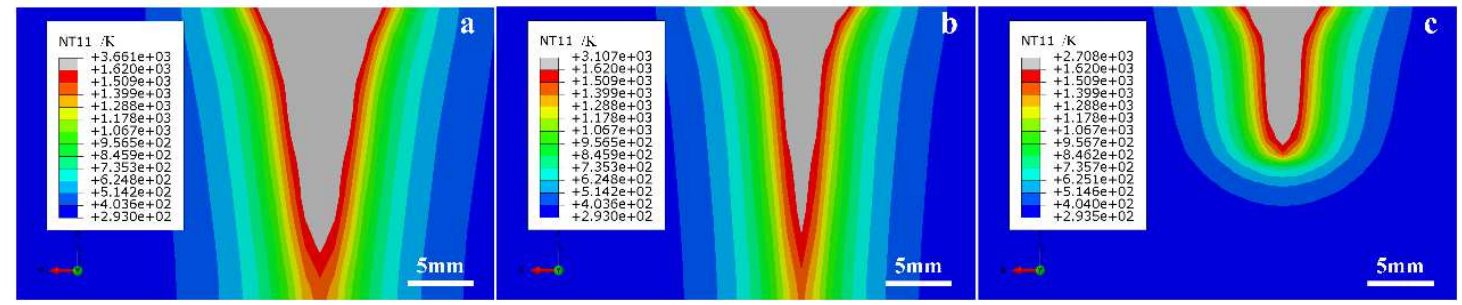

Fig. 9 Weld profiles under different welding speed at welding current of $50 \mathrm{~mA}$

(a) $300 \mathrm{~mm} / \mathrm{min}$; (b) $400 \mathrm{~mm} / \mathrm{min}$; (c) $600 \mathrm{~mm} / \mathrm{min}$

Fig.10 presents the relationship between weld width/penetration and welding speed under 3 kinds of different welding current conditions. As shown in Fig. 10, the weld width/penetration increased as the welding speed reduced in 3 kinds of welding currents. Meanwhile, the decline of weld penetration was enhanced with the increased of welding speed, while the attenuation of weld width was much smaller. For the welding current of $60 \mathrm{~mA}$ (Fig. 10c), as the welding speed increase from $300 \mathrm{~mm} / \mathrm{min}$ to $600 \mathrm{~mm} / \mathrm{min}$, the weld penetration was reduced from $18.5 \mathrm{~mm}$ to $10.5 \mathrm{~mm}$, which was 5.2 times to the weld width. Therefore, the weld penetration has a greater attenuation than weld width with the increase of welding speed, which lead to a diminution in the aspect ratio of the weld (as shown in Fig. 10b and Fig. 10c). There was no obvious variation between the aspect ratio and welding speed under welding current of $40 \mathrm{~mA}$. 

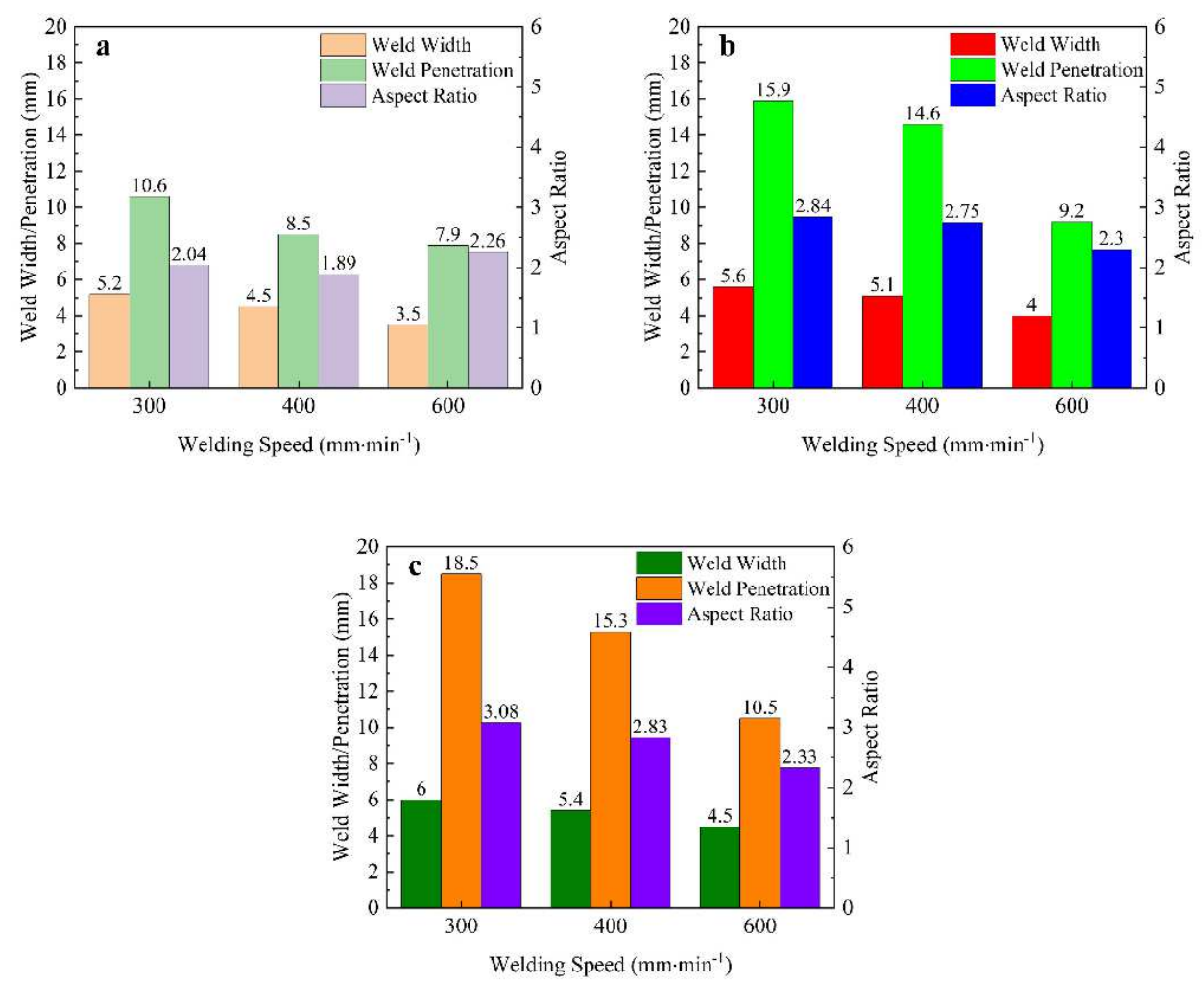

Fig. 10 Weld width/penetration under different welding speed Welding current for (a) $40 \mathrm{~mA}$; (b) $50 \mathrm{~mA}$; (c) $60 \mathrm{~mA}$

\subsection{Validation of temperature field}

Weld profiles were investigated by Leica DMIRM optical microscope to verified temperature field results. Electron beam welding experiments were employed according to the parameters in Table 1. As shown in Fig. 11, the weld morphologies of EBW under 3 different welding parameters were consistent well with the simulated results. The weld width and weld penetration were almost equal with actual weld, which means the temperature fields calculated by the current computational approach could precisely represent realistic situations.

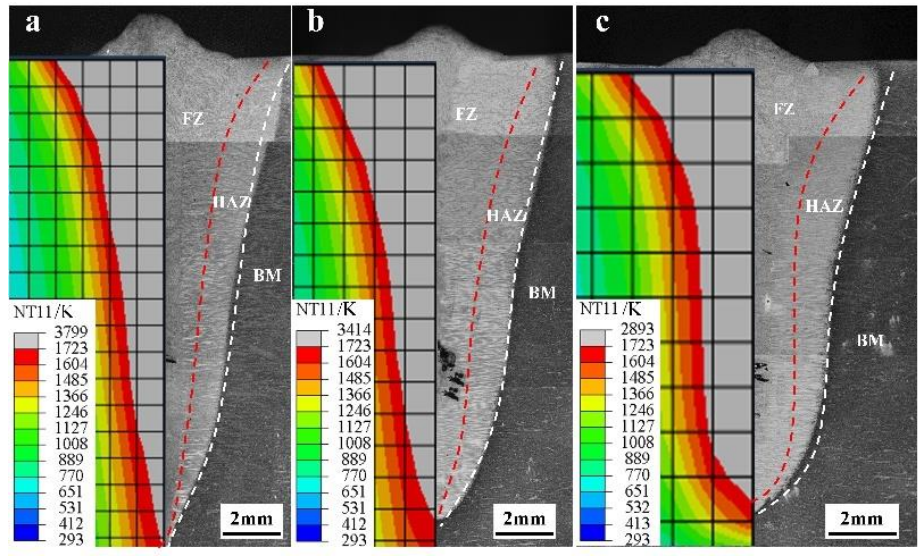

Fig. 11 Comparison with the modeling weld profile under different parameters 
(a) Case 7; (b) Case 8; (c) Case 9

Fig. 12 shows the errors between simulated results and measured results in 9 kinds of welding parameters. As shown in Fig. 12, both errors of weld width and weld penetration were less than $10 \%$.
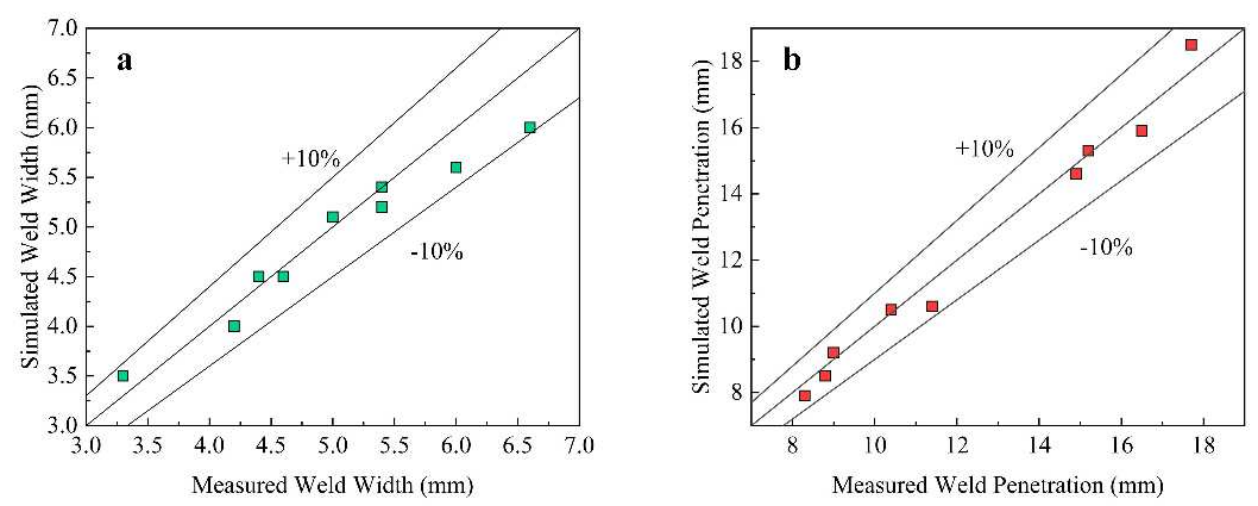

Fig. 12 The distributions of relative errors

(a) distribution of weld width errors; (b) distribution of weld penetration errors

Fig. 13 shows the comparison between the measured thermal cycle curves and the simulated thermal cycle curves at same positions. Simulated thermal cycle curves were shown as solid lines, and measured thermal cycle curves were shown as dotted lines. The measured curves at different positions were in good agreement with the simulated results. At positions of $6 \mathrm{~mm}, 8 \mathrm{~mm}, 10 \mathrm{~mm}, 12 \mathrm{~mm}, 14 \mathrm{~mm}$ from the surface, the differences between simulated peak temperature and measured peak temperature were only $12.8^{\circ} \mathrm{C}, 121.5^{\circ} \mathrm{C}, 22.2^{\circ} \mathrm{C}, 48^{\circ} \mathrm{C}$ and $23.5^{\circ} \mathrm{C}$, respectively. Variation tendency of each thermal cycle curve was basically the same, which verified the effectiveness and reliability of the numerical computation results.

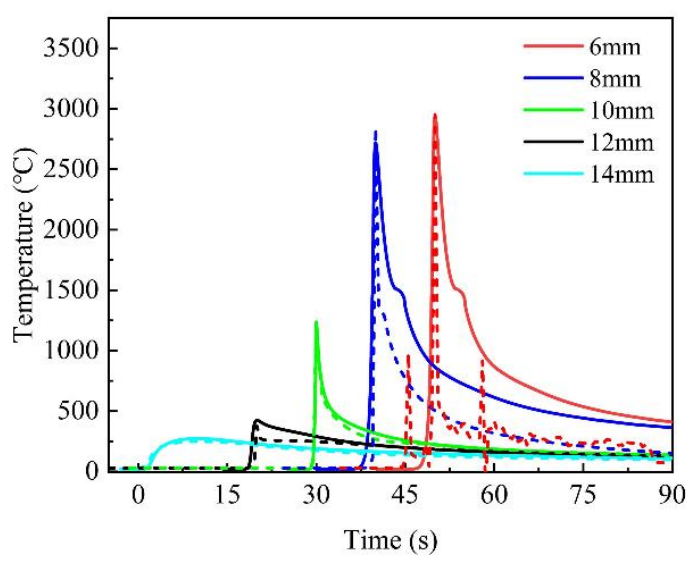

Fig. 13 Verification of welding heat cycle curves

\subsection{Effects of welding parameters on stress field}

Based on the results of temperature fields, the stress fields were obtained by using indirect coupling method. Fig. 14 shows the residual stress distributions of the longitudinal section of welds under different welding parameters. As shown in Fig. 14, 
the values of residual stress increased with the increase of welding speeds under the same welding current. Higher welding current resulted in lower residual stress, which presented in Fig. 14(a), (d) and (g). Residual stresses were basically concentrated around the weld, and decreased sharply in the area far away from weld. Heads and ends of welds represented larger stresses than other locations of weld. Stress reached maximum at the surface of workpiece and lowered with the increase of weld penetration.
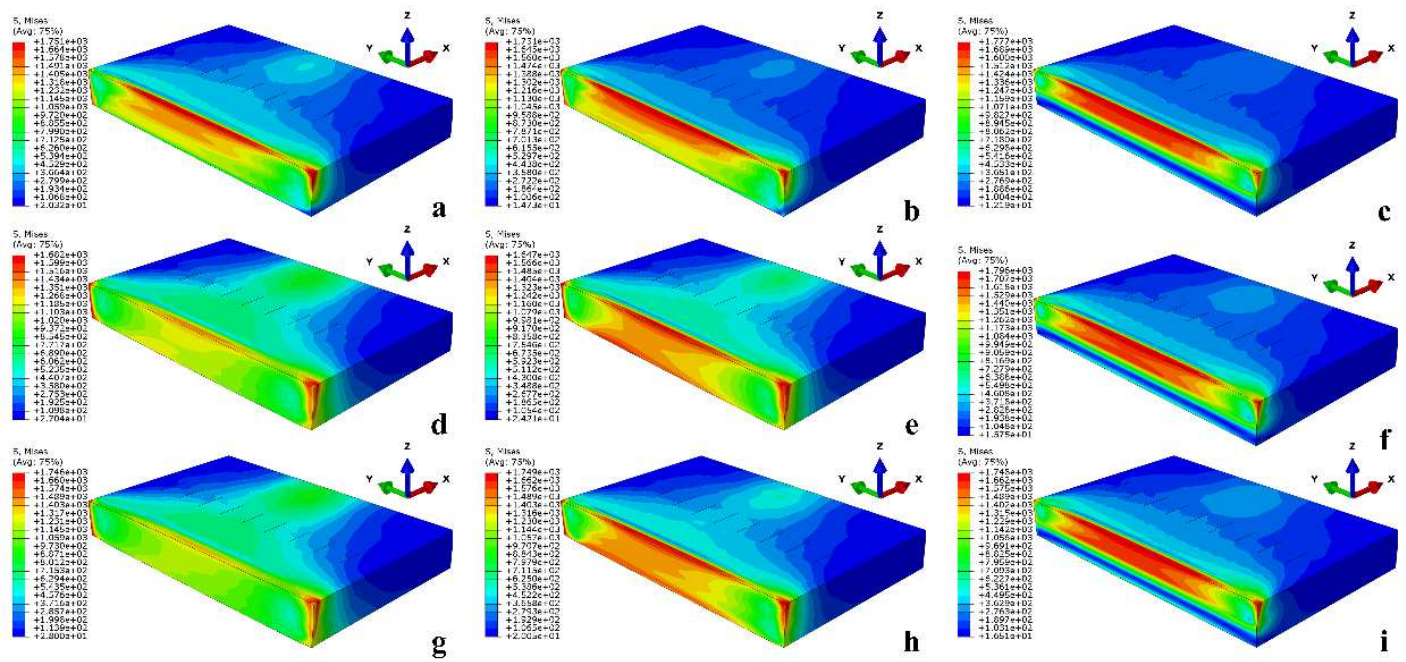

Fig. 14 Stress fields under different cases

(a) (c) case 1 3; (d) (f) case 4 6; (g) (i) case 7 9

In order to illustrate the change rules of residual stress under different welding parameters, the stress values of different welding parameters at the same path were extracted and were shown in Fig. 15. The straight line along the thickness direction at center of weld surface was selected as the path. The residual stress under welding speed of $600 \mathrm{~mm} / \mathrm{min}$ had the maximum values (nearly $1730 \mathrm{MPa}$ at welding current of $50 \mathrm{~mA}$ ), and declined dramatically with increased of the distance from weld surface (shown as chain-dotted lines). As the welding speed decreased, residual stress reduced and no evident changes of stress values were found in different thickness directions (shown as dotted lines and solid lines). At the welding speed of $300 \mathrm{~mm} / \mathrm{min}$, there was a minimum value of residual stress about $1296 \mathrm{MPa}$ at the welding current of 60mA (as shown in solid blue line). It should be known that the effect of phase transition was ignored in the calculation of stress field, which lead to relatively large residual stress. Nevertheless, the values of residual stress in case 4 and case 7 (shown as solid green line and solid blue line respectively) were still lower than the tensile strength of material (shown in Fig. 3b), indicating low risk of crack initiation under these two welding parameters. 


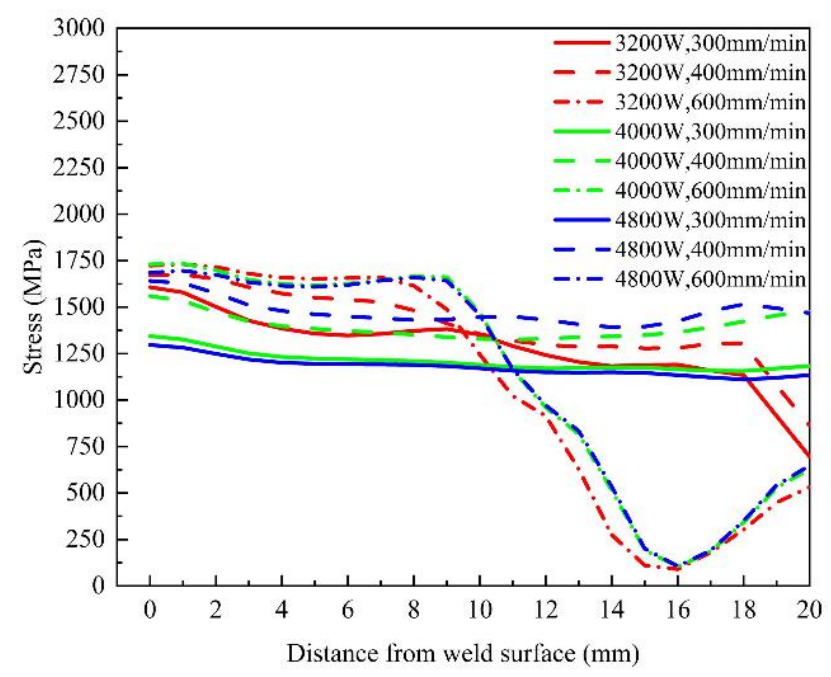

Fig. 15 Mises stress within a same path under different welding parameters

Fig. 16 shows the actual weld morphologies after EBW processes. Severe cracks and defects were found under most of welding parameters, while no obvious defects were found in case $4(50 \mathrm{~mA}-300 \mathrm{~mm} / \mathrm{min})$ and case $7(60 \mathrm{~mA}-300 \mathrm{~mm} / \mathrm{min})$. This was consistent with the simulation results shown as solid blue line and solid green line in Fig 15, which confirmed the accuracy and reliability of the simulated residual stress.

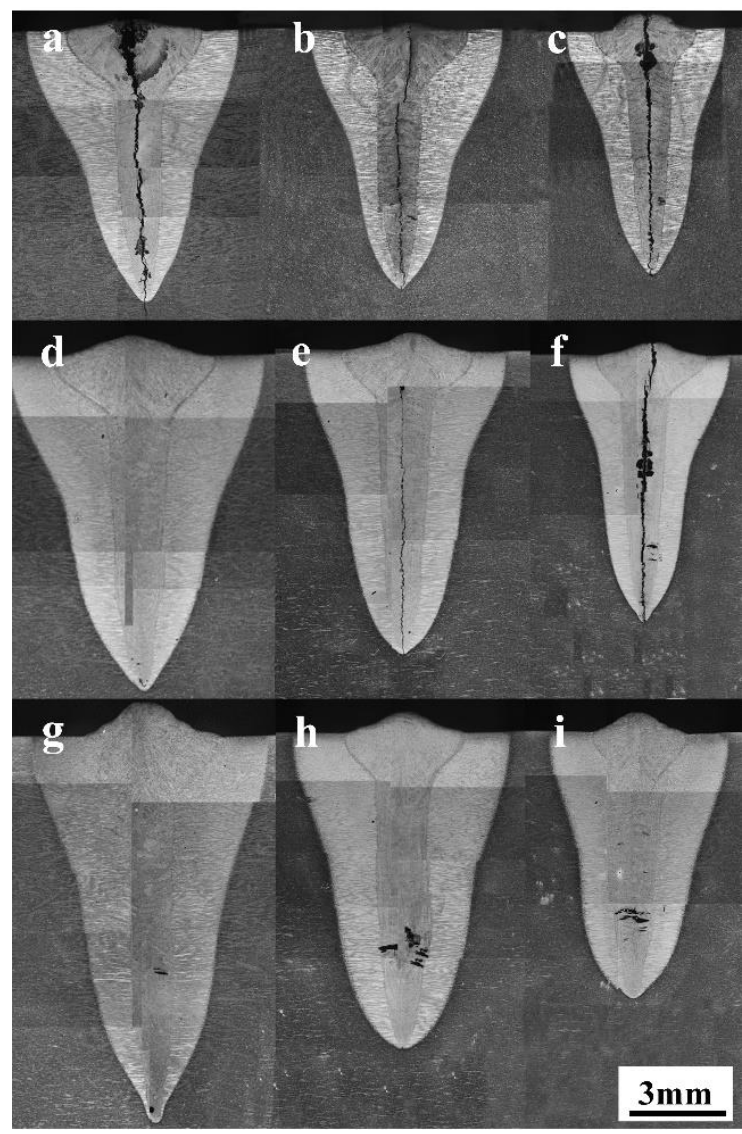

Fig. 16 Weld morphology after EBW processes (a) (c) case 1 3; (d) (f) case 4 6; (g) (i) case 7 9 


\section{Discussions}

In the EBW process of AISI P20 steel, there was a great difference in changes of weld width and penetration with increase of welding current (as shown in Fig. 6 and Fig. 7). The main reason of such a big difference came from the unique heat transfer mode of EBW. Due to the high electron beam energy density and beam concentration, the temperature of the workpiece surface exceeds the boiling point of the material. The vapor pressure of the metal overcomes the surface tension of the liquid metal and pushes the molten metal away, thus forms a beam cavity inside the workpiece called "keyhole" [13,14].The existence of the cavity changes the heat transfer properties inside the metal and forms a high temperature region in the direction of the depth of molten pool, which leads to a nail-shaped or funnel-shaped weld morphology $[35,36]$. In order to illustrate the temperature distribution characteristics of EBW, we extracted temperature data of nodes at different locations under welding parameter of 50mA-300mm/min and plotted thermal heat curves (as shown in Fig. 17). P1 P4 represent positions of $0 \mathrm{~mm}, 2 \mathrm{~mm}, 6 \mathrm{~mm}, 12 \mathrm{~mm}$ from the weld along width direction, and P5 P8 represent the same distances from the weld along depth direction. As shown in Fig. 17a, the temperature at workpiece surface reached over $3500 \mathrm{~K}$, which much higher than the boiling point of base metal. There is a severe attenuation of temperature along the width direction, making the temperature at $\mathrm{P} 4$ only about $500 \mathrm{~K}$. However, the attenuation of temperature along depth direction is much smaller than that of width direction, making the temperature at P8 over $1800 \mathrm{~K}$ (as shown in Fig. $\underline{17 b})$. For this reason, the electron beam has a greater impact on temperature along depth direction, which causes keyhole effect and nail-shape or funnel-shape of the weld. With the increase of welding current, the power of electron beam increases and the keyhole effect is promoted, which leads to greater promotion of weld penetration than weld width (as shown in Fig. 7).
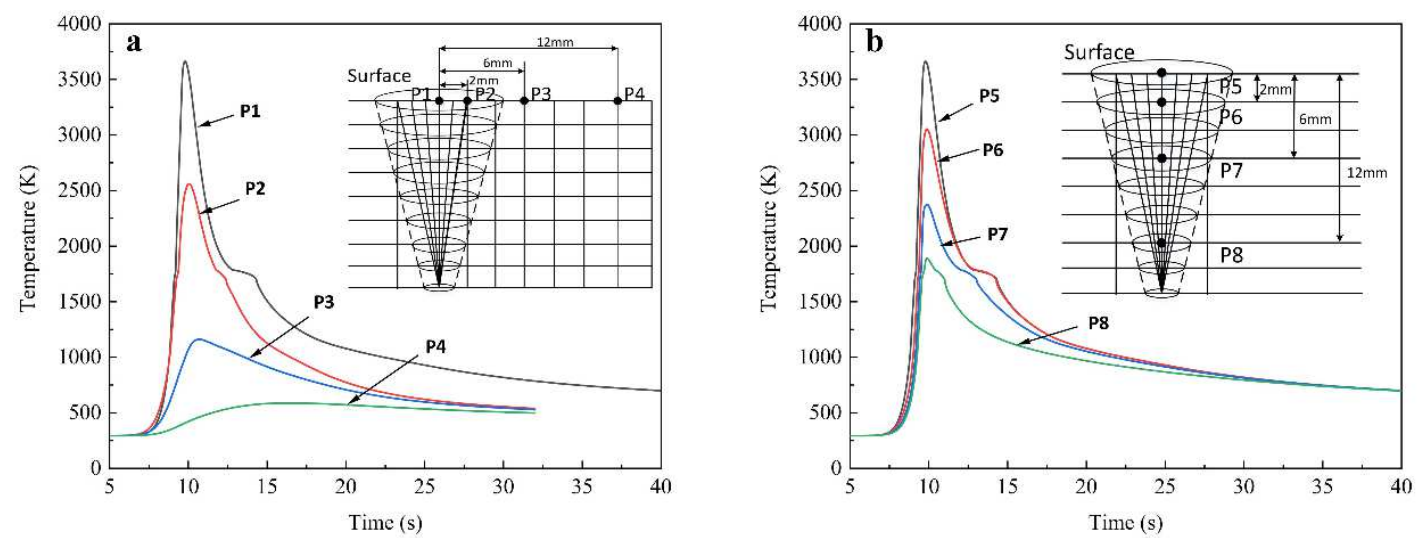

Fig. 17 Welding heat curves at different positions

(a) along the width direction; (b) along the depth direction

Welding speed of EBW plays another important role in affecting weld morphologies and temperature field. The research results from Katayama et al $[37,38]$ showed that the welding speed has great influence on the size of keyhole. In their studies, keyhole produces a certain angle of dip with the movement of electron beam. 
With the increase of welding speed, the inclination of the keyhole increases, which decreases the stability of keyhole and weakens the energy transfer of electron beam. From the above analysis, the impact of keyhole effect on the weld penetration is greater than that of the weld width, making greater attenuation of weld penetration (as shown in Fig. 10). Meanwhile, with constant welding power, increasing welding speed means a decrease in welding line energy, which leads to reduction of weld penetration. On the other hand, due to the increase of welding speed, the interaction time between electron beam and base metal is shortened, the energy input to the workpiece decreases per unit time, which leads to the difficulty of temperature penetration along the depth direction. In the meantime, the heat conduction on the surface is much faster than that in depth direction, which follows that the change of weld width is not obvious relative to that of weld penetration.

The stress field is generated from the non-uniform temperature field during EBW, which is caused by high temperature gradient of heat source and uneven heat transfer. Therefore, the magnitude and distribution range of stress under different welding parameters are strikingly different due to different weld width and penetration (as shown in Fig. 14 and Fig. 15). Fig. 18 shows the temperature and stress curve with time at the same position. As shown in Fig. 18, stress is exquisitely sensitive to temperature changes. The change process of stress can be divided into three stages. In the first stage, stress increases sharply with the increase of temperature, which seems to contradict the softening behavior of metals at high temperature. However, the base metal is subjected to thermal interaction and produces severe deformation before stage I, which causes work hardening of base metal. The effect of work hardening is greater than the effect of material softening in this temperature range, resulting in increase of stress value. In the stage II, as the temperature rises above the melting point of base material, the base metal is melted and the stress drastically drops to zero and is maintained until the temperature drops below the melting point. In the last stage, the temperature drops below melting point and continues to drop. As the metal solidifies gradually, the weld is constrained by solidification, cooling and shrinkage, resulting in thermal stress. As the welding process continues, the thermal stress gradually increased with the decrease of temperature. In this process, the cooling rate has a great influence on the residual stress. The results of Spina et al [39-41] showed that faster cooling increases the residual stress of the welded joint, because the increase of cooling rate would increase the deformation of welded joint and thus increase the thermal stress of the metal due to cooling constraints. In Fig. 15, with the increase of welding speed, the thermal interaction time between electron beam and workpiece is shortened, resulting in rapid loss of heat and acceleration of cooling at the weld. Therefore, the maximum residual stress appears at high welding speed, which is consistent with the studies of Zhang et al [42,43]. With the increase of welding current, the temperature distribution in depth direction is relatively uniform due to the effect of keyhole, which makes small temperature gradient of weld section in the post-welding cooling. The uniform temperature drop makes much lower thermal stress. Consequently, no defects are observed in case 4 and case 7 after EBW (as shown in Fig. $16(\mathrm{~d})$ and $(\mathrm{g})$ ). 


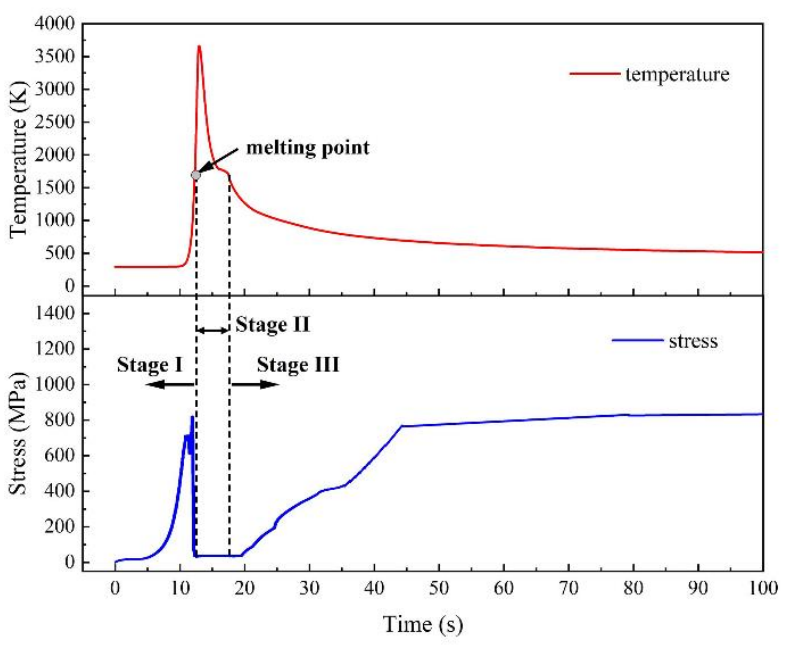

Fig. 18 The relationship between temperature and stress at the same location

According to the results of temperature field and stress field during EBW in VRC process, high quality ultra-heavy AISI P20 plates with thickness of $300 \mathrm{~mm}$ were successfully prepared in Jinan Steel Co., Ltd. With optimized EBW parameter, the edges of the slab showed good qualities and no cracks occurred after hot rolling process (shown as Fig. 19b). Metallographic images of the interface showed that the composite interface is fully healed (shown as Fig. 19c).
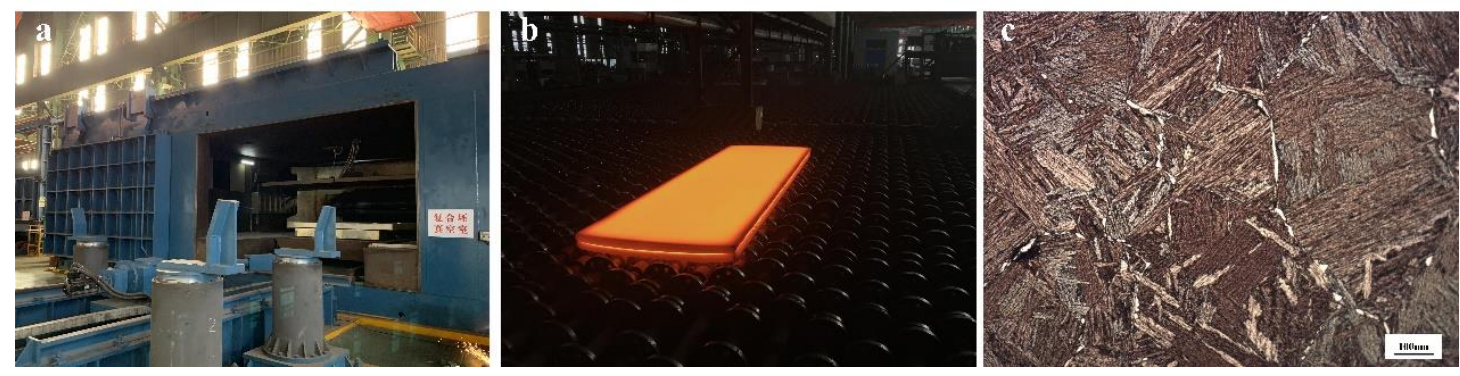

Fig. 19 Production line preparation and interface morphology

(a) EBW system (b) Composite plate prepared by VRC process; (b) Metallography of composite plate interface

\section{Conclusions}

This work was comprehensively performed the electron beam welding process of AISI P20 tool steel by using finite element method. The temperature field and stress field under different welding parameters were obtained with a combined heat source model. According to the analysis of the results, the following conclusions can be drawn:

(1) There is a considerable temperature gradient around the weld due to the existence of keyhole during EBW process, and the keyhole effect leads to a nail-shape or funnel-shape of weld profile. The residual stress is mainly 
concentrated around the weld.

(2) With the same acceleration voltage, weld width and weld penetration increase with the increase of welding current and decrease with the increase of welding speed. The variation of weld penetration is much greater than that of weld width, resulting in various of weld aspect ratio.

(3) The weld morphologies are consistent with the simulated results. The errors of weld width and weld penetration are less than $10 \%$. The thermal cycle curves of modeling are in good agreement with the measured thermal cycle curves, which verified the reliability of the simulated results.

(4) At higher welding speed, the weld has greater residual stress due to faster cooling rate, increasing welding current can be attributed to reduce residual stress. Accordingly, greater aspect ratio of weld resulting in low risk of cracking after EBW. Further, the optimized EBW parameter derived from this study has been successfully applied to the industrial production of ultra-heavy AISI P20 plates.

\section{Declarations}

\section{Funding}

This study was funded by National Key Research and Development Program of China (2017YFB0305004, 2016YFB0300603, 2017YFB0304100). The Fundamental Research for the Chinese Central Universities (N170704013).

\section{Conflicts of interest/Competing interests}

The authors declare that they have no known competing financial interests or personal relationships that could have appeared to influence the work reported in this paper.

\section{Availability of data and material}

The data sets supporting the results of this article are included within the article and its additional files 


\section{Code availability (Not applicable)}

\section{Authors' contributions}

Lanyu Mao: Investigation, Writing - original draft. Zongan Luo: Conceptualization, Methodology, Funding acquisition. Yingying Feng: Investigation, Validation. Xiaoming Zhang: Supervision.

\section{Ethics approval (Not applicable)}

\section{Consent to participate (Not applicable)}

\section{Consent for publication}

Written informed consent for publication was obtained from all participants

\section{References}

[1] Kara F. Optimization of surface roughness in finish milling of AISI P20+S plastic-mold steel. Mater Tehnol 2018;52:195-200. https://doi.org/10.17222/mit.2017.088.

[2] Li Z, Zhang J, Dai B, Liu Y. Microstructure and corrosion resistance property of laser transformation hardening pre-hardened AISI P20 plastic die steel. Opt Laser Technol 2020;122. https://doi.org/10.1016/j.optlastec.2019.105852.

[3] Wu BB, Huang S, Wang ZQ, Zhao JX, Wang CS, Shang CJ, et al. Crystallography analysis of toughness in high strength ultra-heavy plate steel. Mater Lett 2019;250:55-9. https://doi.org/10.1016/j.matlet.2019.04.084.

[4] Zhou T, Yu H, Wang S. Effect of microstructural types on toughness and microstructural optimization of ultra-heavy steel plate: EBSD analysis and microscopic fracture mechanism. Mater Sci Eng A 2016;658:150-8. https://doi.org/10.1016/j.msea.2016.02.001.

[5] Shou-yuan B, Xin Z, Sheng-li L, Lin Z, Wei-juan L, Ling Y. Numerical Simulation, Microstructure, properties of EH40 ultra-heavy plate under gradient temperature rolling. Mater Sci Eng A 2020;791. https://doi.org/10.1016/j.msea.2020.139778.

[6] Wei Y, Gaosheng L, Qingwu C. Effect of a novel gradient temperature rolling process on deformation, microstructure and mechanical properties of ultra-heavy plate. J Mater Process Technol 2015;217:317-26. https://doi.org/10.1016/j.jmatprotec.2014.11.011.

[7] Jang YC, Lee Y, An GB, Park JS, Lee JB, Kim S Il. Temperature dependent 
fracture model and its application to ultra heavy thick steel plate used for shipbuilding. Int J Mod Phys B 2008;22:5483-8.

https://doi.org/10.1142/s0217979208050693.

[8] Preciado WT, Bohorquez CEN. Repair welding of polymer injection molds manufactured in AISI P20 and VP50IM steels. J Mater Process Technol 2006;179:244-50. https://doi.org/10.1016/j.jmatprotec.2006.03.101.

[9] Suarez SA, Suarez AM, Preciado WT. Arc welding procedures on steels for molds and dies. Procedia Eng 2015;100:584-91. https://doi.org/10.1016/j.proeng.2015.01.408.

[10] Wu CS, Ushio M, Tanaka M. Analysis of the TIG welding arc behavior. Comput Mater Sci 1997;7:308-14. https://doi.org/10.1016/s0927-0256(96)00048-1.

[11] Javed M, Khalid Hussain A, Lateef A. Influence of Welding Speed on Tensile Strength of Welded Joint in TIG Welding Process. Int J Appl Eng Res 2010;1:518-27.

[12] Yunlian Q, Ju D, Quan H, Liying Z. Electron beam welding, laser beam welding and gas tungsten arc welding of titanium sheet. Mater Sci Eng A 2000;280:177-81. https://doi.org/10.1016/S0921-5093(99)00662-0.

[13] Luo M, Hu R, Liu T, Wu B, Pang S. Optimization possibility of beam scanning for electron beam welding: Physics understanding and parameters selection criteria. Int J Heat Mass Transf 2018;127:1313-26. https://doi.org/10.1016/j.ijheatmasstransfer.2018.07.014.

[14] Amara EH, Bendib A. Modelling of vapour flow in deep penetration laser welding. J Phys D Appl Phys 2002;35:272-80. https://doi.org/10.1088/0022-3727/35/3/317.

[15] Chen JY, Conlon K, Xue L, Rogge R. Experimental study of residual stresses in laser clad AISI P20 tool steel on pre-hardened wrought P20 substrate. Mater Sci Eng A 2010;527:7265-73. https://doi.org/10.1016/j.msea.2010.07.098.

[16] Kaur A, Ribton C, Balachandaran W. Electron beam characterisation methods and devices for welding equipment. J Mater Process Technol 2015;221:225-32. https://doi.org/10.1016/j.jmatprotec.2015.02.024.

[17] Flint TF, Francis JA, Smith MC, Balakrishnan J. Extension of the double-ellipsoidal heat source model to narrow-groove and keyhole weld configurations. J Mater Process Technol 2017;246:123-35. https://doi.org/10.1016/j.jmatprotec.2017.02.002.

[18] Huang B, Chen X, Pang S, Hu R. A three-dimensional model of coupling dynamics of keyhole and weld pool during electron beam welding. Int J Heat Mass Transf 2017;115:159-73. https://doi.org/10.1016/j.ijheatmasstransfer.2017.08.010.

[19] Wang HX, Chen X. Three-dimensional modelling of the laser-induced plasma plume characteristics in laser welding. J Phys D Appl Phys 2003;36:628-39. https://doi.org/10.1088/0022-3727/36/6/304.

[20] Fu PF, Mao ZY, Lin J, Liu X, Zuo CJ, Xu HY. Temperature field modeling and microstructure analysis of EBW with multi-beam for near $\alpha$ titanium alloy. 
Vacuum 2014;102:54-62. https://doi.org/10.1016/j.vacuum.2013.11.002.

[21] Hong Z, Zhengxing M, Jiukai L, Yongjie L, Qingyuan W. Numerical Simulation of the Electron Beam Welding and Post Welding Heat Treatment Coupling Process. High Temp Mater Process 2018;37:793-800. https://doi.org/10.1515/htmp-2017-0053.

[22] Lacki P, Adamus K. Numerical simulation of the electron beam welding process. Comput Struct 2011;89:977-85. https://doi.org/10.1016/j.compstruc.2011.01.016.

[23] LI Y jun, WU A ping, LI Q, ZHAO Y, ZHU R can, WANG G qing. Effects of welding parameters on weld shape and residual stresses in electron beam welded Ti 2 AlNb alloy joints. Trans Nonferrous Met Soc China (English Ed 2019;29:67-76. https://doi.org/10.1016/S1003-6326(18)64916-7.

[24] Ronda J, Oliver GJ. Consistent thermo-mechano-metallurgical model of welded steel with unified approach to derivation of phase evolution laws and transformation-induced plasticity. Comput Methods Appl Mech Eng 2000;189:361-418. https://doi.org/10.1016/S0045-7825(99)00461-2.

[25] Wei PS, Shian MD. Three-dimensional analytical temperature field around the welding cavity produced by a moving distributed high-intensity beam. J Heat Transfer 1993;115:848-56. https://doi.org/10.1115/1.2911379.

[26] Malik AM, Qureshi EM, Ullah Dar N, Khan I. Analysis of circumferentially arc welded thin-walled cylinders to investigate the residual stress fields. Thin-Walled Struct 2008;46:1391-401. https://doi.org/10.1016/j.tws.2008.03.011.

[27] Karalis DG, Papazoglou VJ, Pantelis DI. Mechanical response of thin SMAW arc welded structures: Experimental and numerical investigation. Theor Appl Fract Mech 2009;51:87-94. https://doi.org/10.1016/j.tafmec.2009.04.004.

[28] Bhatti AA, Barsoum Z, Murakawa H, Barsoum I. Influence of thermo-mechanical material properties of different steel grades on welding residual stresses and angular distortion. Mater Des 2015;65:878-89. https://doi.org/10.1016/j.matdes.2014.10.019.

[29] Hoseiny H, Caballero FG, Martin DS, Capdevilla C. The influence of austenitization temperature on the mechanical properties of a prehardened mould steel. Mater Sci Forum 2012;706-709:2140-5. https://doi.org/10.4028/www.scientific.net/MSF.706-709.2140.

[30] Yan G, Lu S, Zhang M, Wang J, Yang X, Zhang Z, et al. Wear and corrosion behavior of P20 steel surface modified by gas nitriding with laser surface engineering. Appl Surf Sci 2020;530:147306. https://doi.org/10.1016/j.apsusc.2020.147306.

[31] Ho CY, Wen MY, Lee YC. Analytical solution for three-dimensional model predicting temperature in the welding cavity of electron beam. Vacuum 2007;82:316-20. https://doi.org/10.1016/j.vacuum.2007.04.040.

[32] Liu C, He J. Numerical analysis of fluid transport phenomena and spiking defect formation during vacuum electron beam welding of 2219 aluminium alloy plate. Vacuum 2016;132:70-81. 
https://doi.org/10.1016/j.vacuum.2016.07.033.

[33] Wang Y, Fu P, Guan Y, Lu Z, Wei Y. Research on modeling of heat source for electron beam welding fusion-solidification zone. Chinese J Aeronaut 2013;26:217-23. https://doi.org/10.1016/j.cja.2012.12.023.

[34] Petrov P, Tongov M. Numerical modelling of heat source during electron beam welding. Vacuum 2020;171:108991. https://doi.org/10.1016/j.vacuum.2019.108991.

[35] Tan W, Bailey NS, Shin YC. Investigation of keyhole plume and molten pool based on a three-dimensional dynamic model with sharp interface formulation. J Phys D Appl Phys 2013;46. https://doi.org/10.1088/0022-3727/46/5/055501.

[36] Tu JF, Inoue T, Miyamoto I. Quantitative characterization of keyhole absorption mechanisms in $20 \mathrm{~kW}$-class CO2 laser welding processes. ICALEO 2002 - 21st Int Congr Appl Laser Electro-Optics, Congr Proc 2002;192. https://doi.org/10.2351/1.5066122.

[37] Seto N, Katayama S, Matsunawa A. High-speed simultaneous observation of plasma and keyhole behavior during high power $\mathrm{CO} 2$ laser welding: Effect of shielding gas on porosity formation. J Laser Appl 2000;12:245-50. https://doi.org/10.2351/1.1324717.

[38] Matsunawa A, Kim J-D, Seto N, Mizutani M, Katayama S. Dynamics of keyhole and molten pool in laser welding. J Laser Appl 1998;10:247-54. https://doi.org/10.2351/1.521858.

[39] Spina R, Tricarico L, Basile G, Sibillano T. Thermo-mechanical modeling of laser welding of AA5083 sheets. J Mater Process Technol 2007;191:215-9. https://doi.org/10.1016/j.jmatprotec.2007.03.087.

[40] Ma ZY, Feng AH, Chen DL, Shen J. Recent Advances in Friction Stir Welding/Processing of Aluminum Alloys: Microstructural Evolution and Mechanical Properties. Crit Rev Solid State Mater Sci 2018;43:269-333. https://doi.org/10.1080/10408436.2017.1358145.

[41] Ravisankar A, Velaga SK, Rajput G, Venugopal S. Influence of welding speed and power on residual stress during gas tungsten arc welding (GTAW) of thin sections with constant heat input: A study using numerical simulation and experimental validation. J Manuf Process 2014;16:200-11. https://doi.org/10.1016/j.jmapro.2013.11.002.

[42] Zhang XX, Wu LH, Andrä H, Gan WM, Hofmann M, Wang D, et al. Effects of welding speed on the multiscale residual stresses in friction stir welded metal matrix composites. J Mater Sci Technol 2019;35:824-32. https://doi.org/10.1016/j.jmst.2018.11.005.

[43] Deng D, Murakawa H. Numerical simulation of temperature field and residual stress in multi-pass welds in stainless steel pipe and comparison with experimental measurements. Comput Mater Sci 2006;37:269-77. https://doi.org/10.1016/j.commatsci.2005.07.007. 